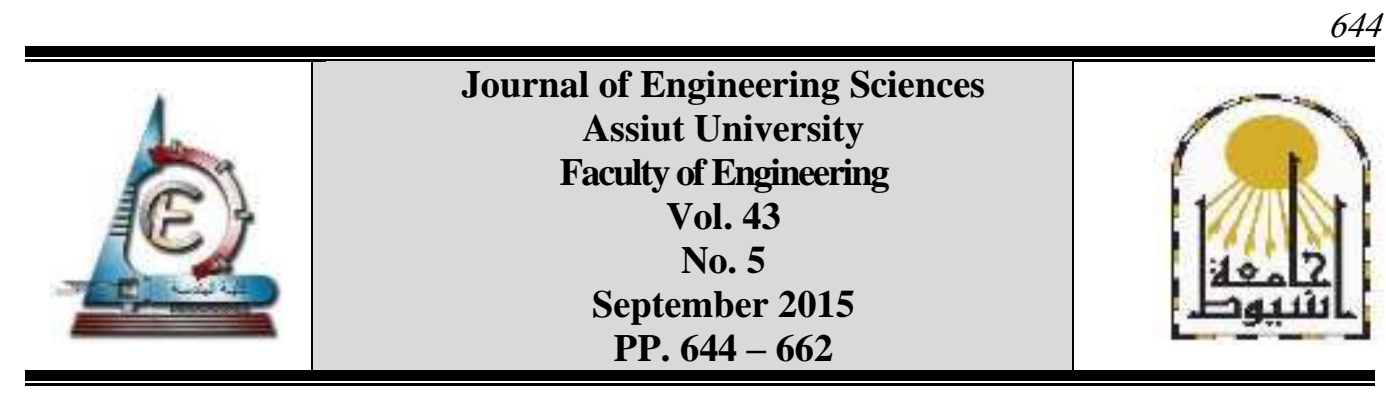

\title{
EVALUATION OF REHABILITATION SOLUTIONS FOR PERFORMANCE OF WATER PIPES NETWORK (CASE STUDY-EL- MINIA NEW CITY NETWORK)
}

\author{
Nashat A. Ali, Gamal Abozeid, Moustafa S. Darweesh and Mohamed Mamdouh * \\ Civil Eng. Dept., Assiut Univ., 71516 Assiut.
}

(Received 29 July 2015; Accepted 15 August 2015)

\begin{abstract}
Aging of pipes and increasing demands placed upon it, have led to system deterioration which causes increase in operation, maintenance costs and decrease in the quality and quantity of water supplied. The water utilities put the plans to overcome these problems by suggesting solutions valid through a predefined period of time. When suggesting these solutions, the utilities mainly concentrate on the cost only without taking into consideration many important factors. In the target year, El-Minia new city network will suffer from many problems such as low pressures and high velocities. In this paper, twelve of demand allocating methods is used to simplify El-Minia network to facilitate the optimization process, and the best method is selected and used. We suggest solutions to the network by using Darwin Designer which is a tool in Bentley WaterGEMS V8i software. In addition, many tools in the software are used to evaluate the suggested solutions according to cost, efficiency, network performance at abnormal conditions and water quality. Finally, the most consistent solution is selected.
\end{abstract}

Keywords: Cost optimization, Rehabilitation, Pump optimization, Water network efficiency, ElMinia new city, Bentley WaterGEMS V8i.

\section{Introduction}

As a system ages, its ability to transport water diminishes as a result of corrosion, breaks and the demands placed upon it typically increase. Improvements of a system performance can be achieved by replacing, rehabilitating, parallel pipes and repairing some of the pipes in the system. Actually it is a difficult problem due to budget limitations. So, in most cases, decisions are made on when and which pipes in the system should be replaced or rehabilitated (Kim et al. [8]).

There are many researchers who dealt with these problems by using multi-objective evolutionary algorithms [3, 4, 7-9 and 17]. Kleiner [9] developed a computer program called MNRAP. By using it, he could select for each pipe, the rehabilitation alternative and the time of its implementation, so as to minimize the cost of the rehabilitation investment

\footnotetext{
* Corresponding author.

Email address: engmohanoty2013@yahoo.com
} 
and al1 maintenance costs over a pre-defined time horizon with achieving certain constraints. (MNRAP) was based on a dynamic programming approach. Cheung et al. [3] presented a comparative study of multi objective genetic algorithm (MOGA) and strength Pareto evolutionary algorithm (SPEA). Cost minimization and minimum pressure requirement were the objectives of the analysis. They concluded that SPEA outperformed MOGA in terms of the Pareto fronts produced and processing time required. Kim et al. [8] presented an optimal planning model for pipe rehabilitation. Capital costs (replacement, rehabilitation and repairing costs) and benefits (by the reduction of pumping cost and leakage cost). KYPIPE was used for checking the hydraulic reliability. They used a new meta-heuristic algorithm and harmony search which outperformed on previous techniques. JIN et al. [7] used a non-dominated sorting Genetic Algorithm-II (NSGA-II) to solve the altered multi-objective optimization model. By introduction of artificial inducement mutation (AIM) operation, they could accelerate the convergence speed of population and improve the rationality and feasibility of solutions. Cisty [4] proposed a method which was a combination between genetic algorithm (GA) and linear programming (LP) and it was called GALP. It used LP because it was more dependable than heuristics methods in finding the global optimum in case of branched networks but, GA was used for decomposing a complex looped network into a group of branched networks. This method produced solutions that were more stable in achieving a global minimum cost. Siew et al. [17] described a penalty-free multi-objective evolutionary optimization approach for the phased whole-life design and rehabilitation of water pipes. The optimization model considered the costs of initial construction, rehabilitation, upgrading, repairs and pipe failure. The model also included the deterioration over time of both the structural integrity and hydraulic capacity of every pipe. Results for two sample networks showed that the algorithm was stable and found optimal and near optimal solutions reliably and efficiently.

Other researchers prioritized and ranked water pipes for repair, replacement, and rehabilitation by using software models [10, 11, 13 and 18]. Tabesh and Saber [18] prepared a conceptual model to prioritize the rehabilitation schemes of pipes by using GIS based on different scenarios with respect to the combination effects of basic factors in physical, hydraulic and experimental categories. They found that the age factor and the pressure had the greatest influence in outlining the final rehabilitation scenario. The importance of the pipe length had decreased considerably as well. Nazif et al. [11] developed a Physical Vulnerability Index (PVI) to evaluate the physical conditions of water mains. They took the pipe characteristics and bedding soil specifications into consideration and used Analytical Hierarchy Process (AHP) to weight these factors. They also developed the System Physical Performance Index (SPVI) which evaluated the pipes according to its hydraulic importance in the system. The genetic algorithm was used to determine ways to improve the system performance. This method was more helpful for decision makers to better chose pipes for rehabilitation. Marzouk et al. [10] presented a model that prioritized the rehabilitation of water mains and assisted in rehabilitation technology selection. Series of interviews and questionnaire surveys were conducted to identify the most important factors that affect water mains deterioration and selection of the rehabilitation technology in Egypt. They used the Simos' procedure to develop the priority index model and the alternative evaluation model. The priority index model was integrated with GIS to prioritize the water pipes to help the decision maker to decide the course of action. Popawala and Shah [13] designed a condition assessment model, based on Analytical Hierarchy Process (AHP), for pipe prioritization and rehabilitation planning. The model ranked the pipes according to the physical, operational, and environmental main factors and 10 sub- 
Nashat A. Ali, et al., Evaluation of rehabilitation solutions for performance of water pipes ...

factors. Also, they weighted these factors according to its effect and importance depends on collected field data. They found that the physical factor represented 49\%, 36\% with operational factor and the environmental was $13 \%$. They found that the pipe age was the most effective sub-factor, pipe material was the second, and the third was the operational pressure then breakage rate. The least important factors were the pipe diameter and the pipe thickness. The AHP model was validated and it was shown good results $(86.4 \%)$.

Pipe break models are very important in rehabilitation of water networks. Park [12] presented a method for the optimal maintenance and conducted it with taking the economical time period of maintenance into consideration. This method analyzed the accuracy of Proportional Hazards Models (PHMs) in predicting break times and estimating the economical timing for water mains replacement. This method also gave the upper and lower bounds of the economical replacement time period by using the survival functions derived from the PHMs. Renaud et al. [14] coped with the wide diversity of data related to detailed description of the pipes and break history of each pipe. They used the break prediction software called "Casses" which based on the LEYP model and made it more usable by the water utilities. Fontana and Morais [5] developed a model called Promethee V. This model was used to help the utility in selecting a set of feasible alternatives for each leakage point in case of multiple points of losses were detected.

Many researchers studied the uncertainty factors that contribute in the rehabilitation process [1, 15 and 16]. Savic [15] made his analysis with many approaches which dealing with risk and uncertainty. These approaches used the redundant methodology, stochastic robustness/risk evaluation models and solving the problem within a single model. Nodal demands and pipe friction characteristics were the uncertain parameters in his analysis. He deal with the problem as a stochastic, constrained optimization problem. He concluded that these factors were important in the rehabilitation or design process. Aghmiuni et al. [1] studied the effect of pipe roughness uncertainty during an operational period on the network performance. They used Monte Carlo Simulation (MCS) to generate probabilistic series of pipe roughness. They concluded that increasing of pipe roughness uncertainty decreases the network performance during the operational period. Shibu and Reddy [16] searched for an optimal design for water distribution network with minimum cost and the constraints were meeting the nodal demands at a predefined reliability and achieving other physical constraints. They used the Cross Entropy (CE) optimization technique with taking the demand uncertainty into consideration. They used Fuzzy Random Variable (FRV) to model the uncertainty water demand in the future. It was shown that there design was robust in comparison with the others.

According to the aforementioned studies, it is observed that it could create solutions to the different problems of water pipe networks and study their effects by using optimization techniques integrated with hydraulic simulators. In this research, solutions to the future problems of El- Minia new city are created and evaluated according to several important factors.

\section{Theoretical considerations}

The rehabilitation problem of water networks can be solved by many optimization techniques. But, here is the genetic algorithm toolbox which in Bentely WaterGEMS V8i is used. The equations of the objective function and constraints are shown below: 


\subsection{The objective function}

Min $F=\sum C_{i j} L_{i j}$

Where $F$ is the total cost of the solution; $L$ is the length of the new replaced or parallel pipe $i j ; C$ is the cost of the new pipe $i j$.

This objective function is subjected to two types of constraints: physical and operational. Physical constraints describe the hydraulic behavior of the system (conservation of mass and energy), whereas operational constraints depend on the allowable conditions defined by the utility throughout the network.

The conservation of mass at junctions is defined as follows;

$$
\sum_{j} Q_{i j, t}=q_{i . l}
$$

where $Q_{i j, t}=$ flow in pipe $i j$ at time $t$; and $q_{i, t}=$ consumption at node $i$ at time $t$. Mass balance in tanks can be written in accordance with the following equation;

$$
\sum_{j} Q_{i j . t}-\frac{S_{i}}{\Delta t}\left(Y_{i, t}-Y_{i, t-\Delta t}\right)=0
$$

where $S_{i}=$ cross-sectional area of tank $i$ (assuming cylindrical tank); $Y_{i, t}=$ water level in tank at time $t$; and $Y_{i, t}-\Delta t=$ tank water level at previous time step. The initial water level for every tank $i Y_{i, 0}$, is known. Both Eqs. (2) and (3) are written for every node at each time $t$. The conservation of energy equation is given as follows;

$$
H_{i, t}-H_{j, t}=R_{i j}\left|Q_{i j, t}\right|^{n-1} Q_{i j, t}
$$

where $H_{i, t}$ and $H_{j, t}=$ heads in starting and ending nodes of pipe/ link $i j$ at time $t ; R_{i j}=$ resistance coefficient for pipe $i j$; and $n=$ exponent of flow term.

Energy conservation for a fluid entering a centrifugal pump $p$ is defined as follows;

$$
H_{p, t}=A_{p} Q_{p, t}^{2}+B_{p} Q_{p, t}+C_{p}
$$

where $A_{p}$ and $B_{p}=$ two resistance coefficients; and $C_{p}=$ shutoff head. Both Eqs. (4) and (5) are written for every pipe/link $i j$ and every pump $p$ at each time $t$. Eq. (5) uses a parabolic curve fit to represent energy conservation for pump $p$. However, higher-order polynomials can also be used for more accurate modeling.

The operational constraints of the problem typically include requirements on nodal pressures, tank levels, and boundary conditions. An important set of constraints is represented by the requirement that, at each node, head is above some minimum required level, $H_{i, t}^{\text {req }}$, for each time interval $t$;

$$
H_{i, t} \geq H_{i, l}^{\mathrm{req}}
$$

If necessary, an upper limit for the nodal head could also be included. In addition to this, the minimum and maximum water levels at all tanks must be constrained for each time interval $t$; 


$$
Y_{i}^{\min } \leq Y_{i, t}
$$

$$
Y_{i, i} \leq Y_{i}^{\max }
$$

where $Y^{\text {min }}{ }_{i}$ and $Y^{\max }{ }_{i}=$ minimum and maximum water levels for tank $i$. In addition to the described constraint, each tank has to be operated in a way that ensures that there is at least as much water left in the tank at the end of the day, $Y_{i, t}$, as was present at the beginning of that day, $Y_{i, 0}$. This ensures that the tank can be used to balance water in the distribution system for the following day. This constraint is formulated in this paper as follows (Giacomello et al. [6]);

$$
Y_{i, T} \geq Y_{i, 0}
$$

The operational constraints also contained velocity limitations which are;

$$
\begin{aligned}
& V^{\min } \leq V_{i j, t} \\
& V_{i j, t} \leq V^{\max }
\end{aligned}
$$

Where $V_{i j, \mathrm{t}}=$ water velocity of pipe $i j$ at time $t, V^{\min }$ and $V^{\max }=$ minimum and maximum water velocities in pipe.

\section{Case study}

This research is performed for El-Minia new city drinking water distribution network as shown in Fig. (1). There is one source of water feeding the network with water level $=150.96 \mathrm{~m}$, from which the water is pumped into the network as in Fig. (1) with a circular elevated tank of $19.4 \mathrm{~m}$ diameter and height of $10.15 \mathrm{~m}$. It is assumed that the tank is full at the beginning of the time period ( 24 hours). Elevations of the network junctions, average base demands for the different junctions and time demand pattern are taken into consideration. The distribution system shown in Fig. (1) composes of $188 \mathrm{Km}$ of different diameter pipelines. All pipes are Poly Vinyl Chloride (PVC) and the head loss in each pipe is computed using Hazen-Williams formula.

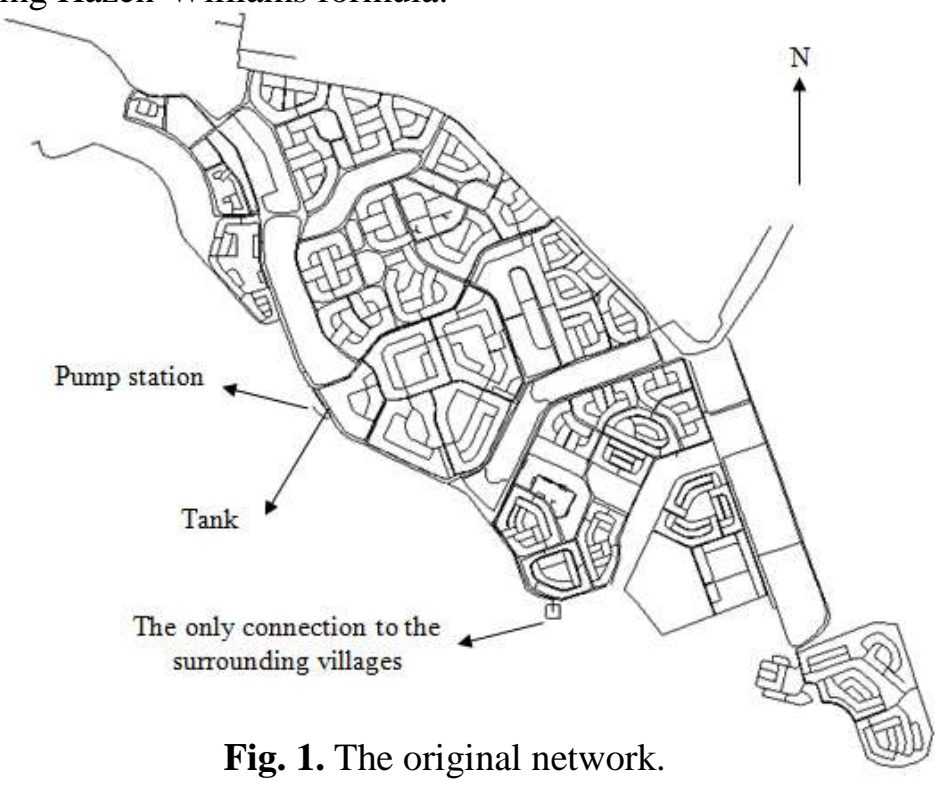


649

JES, Assiut University, Faculty of Engineering, Vol. 43, No. 5, September 2015, pp. $644-662$

\section{Methodology}

The methodology of this research is illustrated in Fig. (2). This methodology consists of the following steps:

1- Predicting the performance of the original network in year 2045.

2- Simplification of the original network to the main network.

3- Investigation of the future problems.

4- Searching for optimal solutions.

5- Comparison between solutions according to many important factors.

6- Selection of the optimum solution.

7- Evaluation of the original network performance after applying the optimum solution.

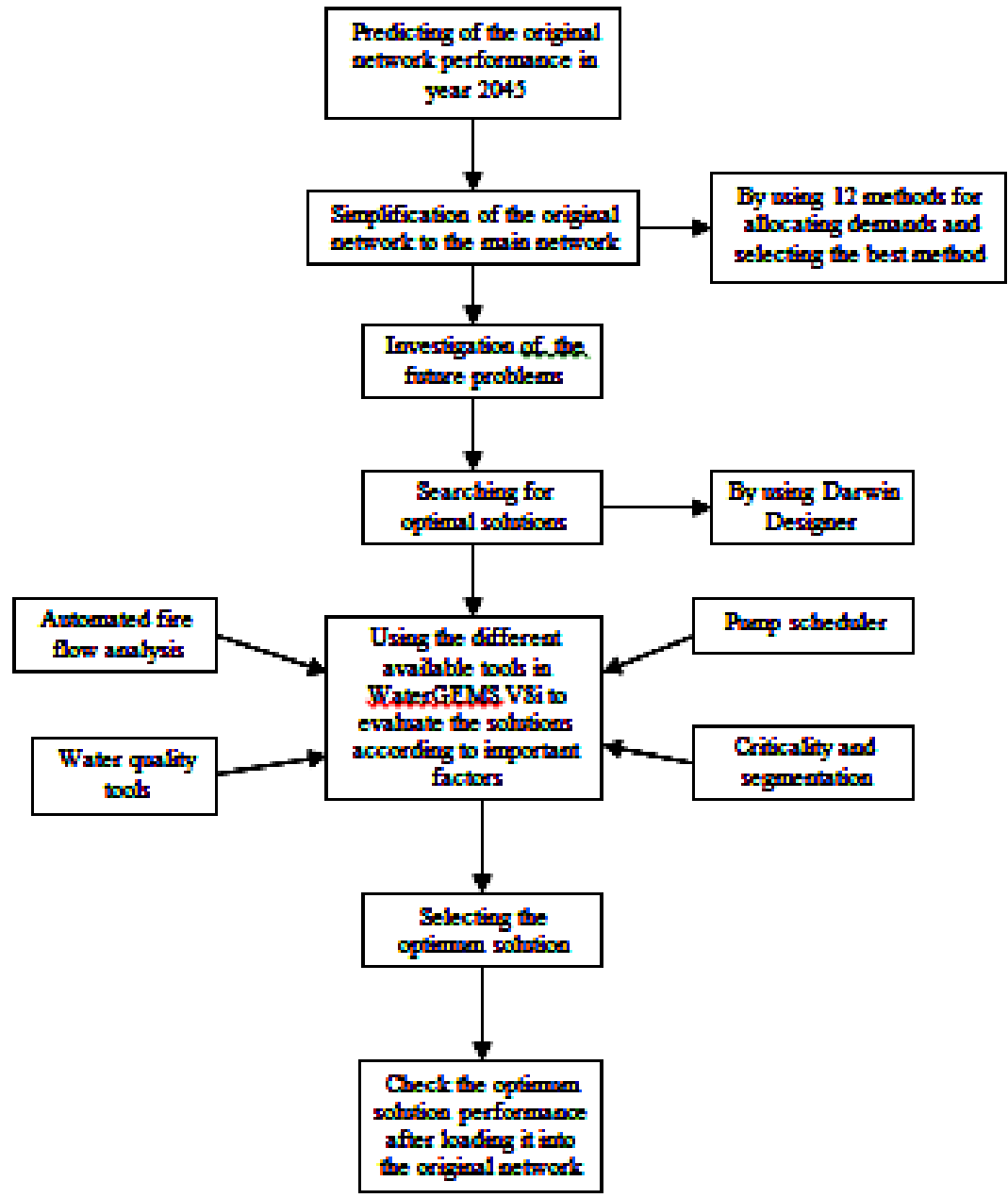

Fig. 2. Schematic diagram of overall research methodology.

\section{Results and discussions}

5.1. Predicting the performance of the original network in year 2045

The conditions of the original network in year 2045 are assumed as follows: 
Nashat A. Ali, et al., Evaluation of rehabilitation solutions for performance of water pipes ...

1- The pump station of this network will not serve any surrounding villages unlike its currently condition (the pump station in year 2015 supplies the surrounding villages with $145.41 \mathrm{~L} / \mathrm{s})$.

2- The Hazen-Williams coefficient for all pipes is equal to 110.

3- The consumption of water is $300 \mathrm{~L} /$ capita/day and the population in year 2045 is predicted by the water utility.

4- There aren't additional water sources or tanks in year 2045.

5- It is assumed that the pump head is kept constant in the future with maintaining the same pressure requirements.

6- There aren't any extensions in the network in year 2045 (it has the same size of the network in year 2015).

7- The demand factor along the day hours in years 2015 and 2045 are listed in Table (1) as measured and predicted by the responsible water utility in El- Minia city.

Table 1.

The demand factor along the day hours in years 2015 and 2045.

\begin{tabular}{|c|c|c|c|c|l|}
\hline Time from Start (hours) & 2015 & 2045 & Time from Start (hours) & 2015 & 2045 \\
\hline 1 & 0.98 & 0.46 & 13 & 1.02 & 1.49 \\
\hline 2 & 0.97 & 0.47 & 14 & 1.03 & 1.35 \\
\hline 3 & 0.97 & 0.48 & 15 & 1.03 & 1.11 \\
\hline 4 & 0.97 & 0.52 & 16 & 1.03 & 1.0 \\
\hline 5 & 0.97 & 0.56 & 17 & 1.03 & 1.06 \\
\hline 6 & 0.96 & 0.6 & 18 & 1.02 & 1.09 \\
\hline 7 & 0.96 & 0.76 & 19 & 1.02 & 1.06 \\
\hline 8 & 1.0 & 1.0 & 20 & 1.02 & 1.0 \\
\hline 9 & 1.0 & 1.35 & 21 & 1.02 & 0.9 \\
\hline 10 & 1.01 & 1.45 & 22 & 1.0 & 0.82 \\
\hline 11 & 1.01 & 1.53 & 23 & 0.96 & 0.64 \\
\hline 12 & 1.02 & 1.56 & 24 & 0.98 & 0.45 \\
\hline
\end{tabular}

\subsection{Simplification of the original network to the main network}

The original network consists of 1348 pipes and 943 junctions, these numbers are very large when dealing with optimization problems by using the features of Bentely WaterGEMS V8i. Reducing the size of the network without affecting on it's performance, gives good optimization results. So, the original network is simplified to the main network (243 pipes and 221 junctions) as shown in Fig. 3. The simplification process is based on eliminating the pipes that have a diameter of $100 \mathrm{~mm}$, because the Egyptian code dictate that the pipe's diameter shouldn't be less than $200 \mathrm{~mm}$ in the main networks and $100 \mathrm{~mm}$ in the secondary network. The main network is shown in Fig. 4.

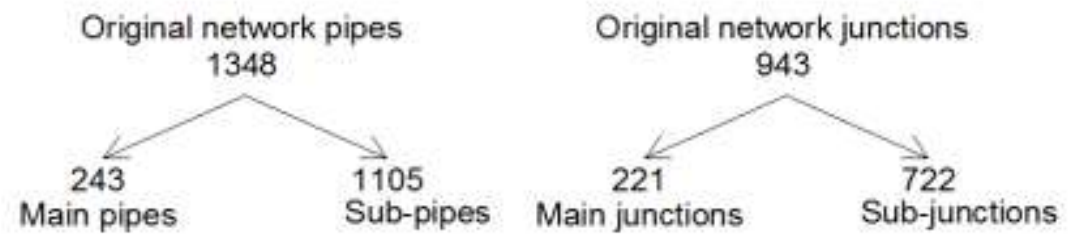

Fig. 3. Simplification of the original network to the main network. 


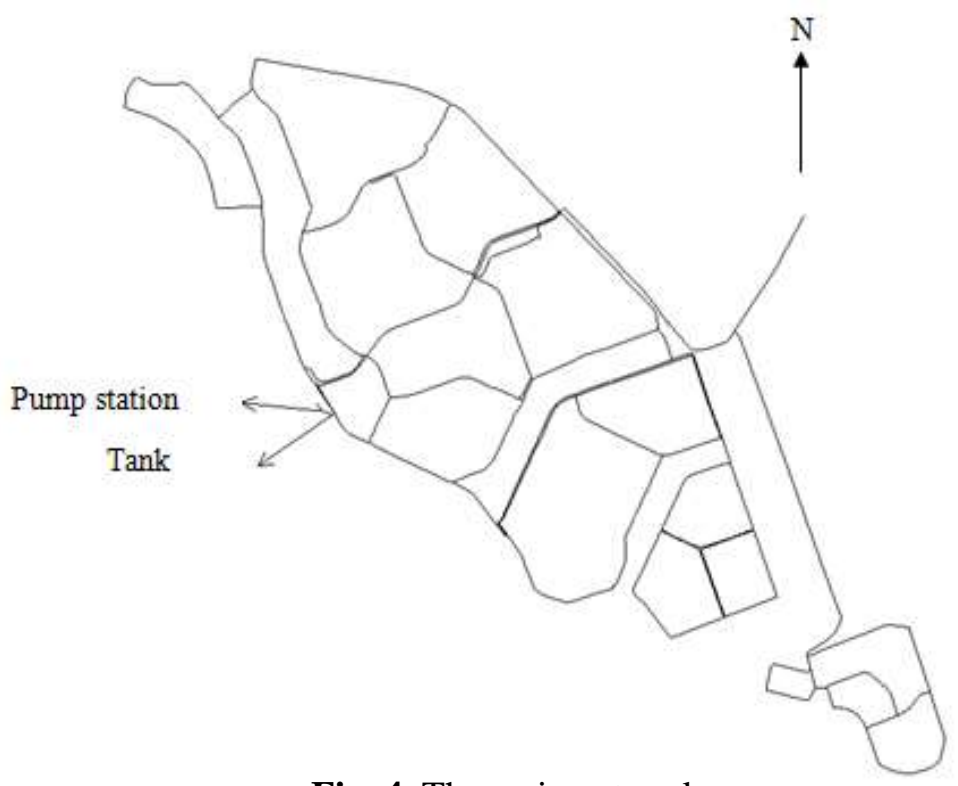

Fig. 4. The main network.

Twelve of the allocating demand methods, some of them are in WaterGEMS V8i, are used for this purpose. The best method is that produces flows in the main pipes very close to flows of the same pipes in the original network. These methods and their index values are shown in Table (2).

Table .2.

The twelve demand allocation methods and their index value.

\begin{tabular}{|c|c|}
\hline Method & *Index(L/S) \\
\hline Billing Meter Aggregation & 7178.239 \\
\hline Nearest Node & 7182.487 \\
\hline Nearest Pipe-Equal Distribution & 7604.123 \\
\hline Nearest Pipe- Distance Weighted & 7607.187 \\
\hline Nearest Pipe- Closest Node & 7595.891 \\
\hline Nearest Pipe- Farthest Node & 7648.415 \\
\hline Equal Flow Distribution & 7085.6 \\
\hline Proportional Distribution by Area & 7971.748 \\
\hline Unit Line & 7940.763 \\
\hline Proportional Distribution by pipe's length & 8301.714 \\
\hline $\begin{array}{c}\text { Proportional Distribution by Area } \\
\text { based on basic demand of main junctions }\end{array}$ & 8037.377 \\
\hline Equal Flow Distribution based on basic demand of main junctions & 7275.228 \\
\hline
\end{tabular}

* Index is the sum of discrepancies between the flow of pipes, produced from the previous methods, on the main network and the flows of the same pipes in the original network. From Table (2), It is observed that the best method is the equal distribution method.

\subsection{Investigation of the future problems}

The main network in year 2045 will suffer from many problems such as: 
Nashat A. Ali, et al., Evaluation of rehabilitation solutions for performance of water pipes ...

1- $40 \%$ of the junctions have pressures less than $30 \mathrm{~m}$ of water and $53 \%$ of them have negative pressures.

2- $16.5 \%$ of the pipes have velocities larger than $2 \mathrm{~m} / \mathrm{s}$.

3- The network failed in fighting fires when conducting automated fire flow analysis which is one of the WaterGEMS's tools.

Note: These numbers are obtained from analyzing the network in steady state case.

\subsection{Searching for optimal solutions}

Two rehabilitation scenarios are conducted which are:

1- Replacement.

2- Parallel pipes.

\subsubsection{Replacement}

This technique offers two choices: First, changing old pipe $(C=110)$ with a new one $(C=150)$ which it's diameter is larger or equal or less than the diameter of the old pipe. Second, the diameter remains as it. The diameters of the new pipelines and its costs, which are available for the design, are shown in Table (3).

Table 3.

The available new pipe's diameter for replacement and it's cost (These costs include material, fittings and construction costs).

\begin{tabular}{|c|c|c|c|}
\hline Diameter $(\mathrm{mm})$ & Cost (L.E/m) & Diameter $(\mathrm{mm})$ & Cost (L.E/m) \\
\hline 50 & 50 & 400 & 400 \\
\hline 100 & 100 & 500 & 500 \\
\hline 150 & 150 & 600 & 600 \\
\hline 175 & 175 & 700 & 700 \\
\hline 200 & 200 & 800 & 800 \\
\hline 225 & 225 & 900 & 900 \\
\hline 250 & 250 & 1000 & 1000 \\
\hline 300 & 300 & & \\
\hline
\end{tabular}

\subsubsection{Replacement solutions}

Solution 1 costs: $3,189,728.0 \quad$ L.E

Solution 2 costs: $7,259,075.0 \quad$ L.E

Solution 3 costs: $14,457,955.0 \quad$ L.E

The three solutions achieve pressure constraints (P > $30 \mathrm{~m}$ of water) along the day and tank constraint but, solution 1 doesn't achieve velocity constraint (28\% of pipes have velocity higher than $2 \mathrm{~m} / \mathrm{s}$ during the steady state case). The big difference in the cost among the solutions is due to the methods, which produce these solutions. In solution 1, we specify a group of pipes which compose of a track between unsafe nodes (Pressure < $30 \mathrm{~m}$ of water) and the water source. After that, this group is identified to Darwin Designer which is a tool in WaterGEMS V8i to search for an optimum solution. Because of the higher velocities in the solution 1, the pipes which have high velocities are replaced with others have large diameters to reduce their velocities to $2 \mathrm{~m} / \mathrm{s}$ or less, this method produces solution 2. Solution 3 results from replacing all pipes in the main network, based on classical method of design which assumes that the velocity $=1 \mathrm{~m} / \mathrm{s}$. Solution 3 is 
impractical because it supposes all pipes will be changed at the same time. The percentage of pipes that are replaced in the previous solutions are shown in Table (4).

Table 4.

The percentage of the new pipes in the three solutions.

\begin{tabular}{|c|c|}
\hline Solutions & Number of new pipes \\
\hline S1 & $82(34 \%)$ \\
\hline S2 & $116(48 \%)$ \\
\hline S3 & $243(100 \%)$ \\
\hline
\end{tabular}

\subsubsection{Parallel pipes}

This approach is conducted in Darwin Designer with two choices: First, supplies the old pipe $(c=110)$ with a new one $(c=150)$ in parallel, the length of the parallel pipe equals to that of the old one but, it's diameter may be different from the old one. Second, leaves the old pipe as it (the diameter of the parallel pipe equals zero). The diameters of the parallel pipes and its costs are shown in Table (3).

\subsubsection{Parallel pipes solutions}

Solution 4 costs 3,133,936.0 L.E

The Solution 4 achieves pressure constraints along the day hours and tank constraint but it doesn't achieve velocity constraint ( $8 \%$ of pipes have velocity higher than $2 \mathrm{~m} / \mathrm{s}$ ). This solution contains 74 new parallel pipes.

Note: Darwin Designer doesn't accept a path of critical pipes for parallel pipes solutions such as in the replacement solutions.

\subsection{Comparison between solutions according to main basic factors}

Bentely WaterGEMS V8i contains many important tools for performance of pipe network solutions. These tools test various important factors concerned with water networks performance. These tools enable us to judge on the adequacy of the previous solutions. The important factors are classified into four main factors; every main factor consists of sub factors as shown in Table (5).

Table 5.

The four basic factors and its sub factors.

\begin{tabular}{|c|c|}
\hline Main factors & Sub factors \\
\hline \multirow{4}{*}{ Cost } & Cost of construction \\
\hline & Cost of pump operation \\
\hline & Cost of maintenance \\
\hline & Pump optimization benefit \\
\hline \multirow{3}{*}{ Efficiency } & Achieving pressure constraints \\
\hline & Achieving velocity constraints \\
\hline & The ability to fight fires \\
\hline \multirow{4}{*}{ Network performance during the abnormal conditions } & Closing any pipe \\
\hline & Leakage \\
\hline & Closing pump suddenly \\
\hline & After life time \\
\hline \multirow{2}{*}{ Water quality } & Chlorine distribution \\
\hline & Water age \\
\hline
\end{tabular}


Nashat A. Ali, et al., Evaluation of rehabilitation solutions for performance of water pipes ...

\subsubsection{Cost}

The cost of a solution consists of four parts which are:

\subsubsection{Cost of construction}

It contains the cost of the new pipes, installations and its construction cost. It is assumed that these costs are equally distributed over 30 years. The cost of the solutions is summarized in Table (6).

\section{Table 6.}

The construction cost for the four solutions.

\begin{tabular}{|c|c|c|}
\hline Solutions & Construction cost (L.E) & Annual cost (L.E) \\
\hline S1 & $3,189,728.0$ & $106,325.0$ \\
\hline S2 & $7,259,075.0$ & $241,970.0$ \\
\hline S3 & $14,457,955.0$ & $481,932.0$ \\
\hline S4 & $3,133,936.0$ & $104,465.0$ \\
\hline
\end{tabular}

\subsubsection{Cost of pump operation}

It is assumed that the energy price is constant along the day hours and equals to $0.3 \mathrm{~L} . \mathrm{E}$ per KWh. The operation costs are calculated as shown in Table (7).

Table 7.

The operation cost of the solutions.

\begin{tabular}{|c|c|c|}
\hline Solution & $\begin{array}{c}\text { Daily energy } \\
\text { consumption (KWh) }\end{array}$ & $\begin{array}{c}\text { Annual cost } \\
\text { (L.E) }\end{array}$ \\
\hline S1 & $23,716.1$ & $2,596,913.0$ \\
\hline S2 & $23,716.1$ & $2,596,913.0$ \\
\hline S3 & $23,716.1$ & $2,596,913.0$ \\
\hline S4 & $32,543.8$ & $3,563,547.0$ \\
\hline
\end{tabular}

\subsubsection{Cost of maintenance}

The cost of maintenance decreases as the solution has many new pipes. In addition to that, as the pipes age, it becomes more likely to break. In other words, the break rate becomes higher. All pipes in the network are in service at the same time so the pipes age isn't taken into consideration. It is assumed that the maintenance cost for all diameters is constant and the maintenance cost is $35 \%$ of the old pipes cost. This cost represents the spares of the old pipes. The cost of old pipes and spares are listed in Table (8).

Table 8.

The maintenance cost of the solutions.

\begin{tabular}{|c|c|c|c|}
\hline Solution & $\begin{array}{c}\text { Number of the } \\
\text { old pipes }\end{array}$ & $\begin{array}{c}\text { Cost of the old } \\
\text { pipes (L.E) }\end{array}$ & $\begin{array}{c}\text { The annual maintenance cost } \\
\text { (L.E) }\end{array}$ \\
\hline S1 & $161(66 \%)$ & $12,524,501.0$ & $146,120.0$ \\
\hline S2 & $127(52 \%)$ & $9,718,842.0$ & $113,387.0$ \\
\hline S3 & 0 & 0 & 0 \\
\hline S4 & $243(100 \%)$ & $15,200,505.0$ & $177,340.0$ \\
\hline
\end{tabular}

\subsubsection{Pump optimization benefit}

It means the ability to save energy from a solution by using an optimized pump schedule. This schedule should achieve at least pressure constraint among three main constraints which are pressure, velocity and tank constraints (ensuring that the tanks 
recover their levels by the end of the day). The only objective of this process is reducing energy consumption. This objective is achieved by providing the Darwin scheduler (an advanced tool in WaterGEMS V8i) with multi choices concerned with the number of opening and closing the pump in one hour. The pump optimization is conducted by taking one action hourly (action means either turn off or turn on), two actions (hydraulic time step is $30 \mathrm{~min}$ ) hourly, three actions (hydraulic time step is $20 \mathrm{~min}$ ) hourly and four actions (hydraulic time step is $15 \mathrm{~min}$ ) hourly. Finally, it is found that taking three actions hourly gives the best results. It achieved pressure constraint only, but violated the velocity and tank constraints. The results of conducting the pump optimization on the previous solutions are evident in Table (9).

Table 9.

Energy saved by pump optimization for the four solutions (hydraulic time step is $20 \mathrm{~min}$ ).

\begin{tabular}{|c|c|c|c|c|}
\hline Solution & $\begin{array}{c}\text { Energy before } \\
\text { optimization KWh } \\
\text { (daily) }\end{array}$ & $\begin{array}{c}\text { Energy after } \\
\text { optimization KWh } \\
\text { (daily) }\end{array}$ & $\begin{array}{c}\text { Saved energy } \\
\text { KWh (daily) }\end{array}$ & $\begin{array}{c}\text { Saved cost } \\
\text { L.E (annually) }\end{array}$ \\
\hline S1 & $23,716.1$ & $23,270.1$ & 446 & $48,837.0$ \\
\hline S2 & $23,716.1$ & $23,256.6$ & 459 & $50,261.0$ \\
\hline S3 & $23,716.1$ & $23,266.1$ & 450 & $49,275.0$ \\
\hline S4 & $23,716.1$ & $23,716.1$ & 0 & 0 \\
\hline
\end{tabular}

5.5.1.5. Evaluation of the solutions according to the total cost

From Tables (6 to 9), it can identify the cheapest solution as shown in Table (10).

Table 10.

Comparison among the various solutions according to the total annual cost.

\begin{tabular}{|c|c|c|c|c|c|}
\hline Solution & $\begin{array}{c}\text { Construction } \\
\text { cost (L.E) }\end{array}$ & $\begin{array}{c}\text { Operation cost } \\
\text { (L.E) }\end{array}$ & $\begin{array}{c}\text { Maintenance } \\
\text { cost (L.E) }\end{array}$ & $\begin{array}{c}\text { Saved } \\
\text { operation } \\
\text { cost (L.E) }\end{array}$ & $\begin{array}{c}\text { The sum } \\
\text { (L.E) }\end{array}$ \\
\hline S1 & $106,325.0$ & $2,596,913.0$ & $146,120.0$ & $-48,837.0$ & $2,800,521.0$ \\
\hline S2 & $241,970.0$ & $2,596,913.0$ & $113,387.0$ & $-50,261.0$ & $2,902,009.0$ \\
\hline S3 & $481,932.0$ & $2,596,913.0$ & 0 & $-49,275.0$ & $3,029,570.0$ \\
\hline S4 & $104,465.0$ & $3,563,547.0$ & $177,340.0$ & 0 & $3,845,352.0$ \\
\hline
\end{tabular}

\subsubsection{Efficiency}

The efficiency of a solution increases when it can achieve these constraints: pressure constraint, velocity constraint and the ability to fight fires.

\subsubsection{Pressure constraint}

It means that the pressure at any node shouldn't be less than $30 \mathrm{~m}$ of water along the day hours. The results of this constraint are shown in Table (11).

Table 11.

The number of nodes that have pressure less than $30 \mathrm{~m}$ of water.

\begin{tabular}{|c|c|}
\hline Solution & Number of nodes that have pressure $<30$ m of water \\
\hline S1 & 0 \\
\hline S2 & 0 \\
\hline S3 & 0 \\
\hline S4 & 0 \\
\hline
\end{tabular}


Nashat A. Ali, et al., Evaluation of rehabilitation solutions for performance of water pipes ...

It is obvious that this factor is useless because the previous mentioned solutions are primarily generated for achieving the pressure constraint and any other solution doesn't achieve this constraint is eliminated.

\subsubsection{Velocity constraint}

The velocity of flow through a pipe should be less than $2 \mathrm{~m} / \mathrm{sec}$ to maintain the lifetime of the pipe and to avoid the excessive water hammer effect. The results of the solutions are tabulated in Table (12).

Table 12.

The number of pipes that have velocities larger than $2 \mathrm{~m} / \mathrm{sec}$.

\begin{tabular}{|c|c|}
\hline $\begin{array}{c}\text { Solu } \\
\text { tion }\end{array}$ & $\begin{array}{c}\text { Number of pipes that have velocity }>2 \\
\mathrm{~m} / \mathrm{sec}\end{array}$ \\
\hline S1 & $69(28.4 \%)$ \\
\hline S2 & 0 \\
\hline S3 & 0 \\
\hline S4 & $26(8.2 \%)$ \\
\hline
\end{tabular}

\subsubsection{The ability to fight fires}

One of the primary goals of a water distribution system is to provide adequate capacity to fight fires. Bentley WaterGEMS V8i automated fire flow analysis can be used to determine if the system can meet the fire flow demands while maintaining minimum pressure constraints or not. Fire flows are computed at each node by iteratively assigning demands and computing system pressures. The fire flow demand is assigned to a node and checks the model, checking to see if all pressure and velocity constraints ( $\mathrm{P}>30 \mathrm{~m}$ of water and $\mathrm{V}<2 \mathrm{~m} / \mathrm{sec}$, respectively) are met at that demand. If a constraint is not met, the flow is reduced until the constraint is just satisfied. If all constraints are exceeded, the fire flow is increased until the constraint is barely met within a tolerance. The analysis automatically rechecks the system pressures if a constraint is violated. Iterations continue until the constraints are met, or until the maximum number of iterations is reached (WaterGEMS V8i User's Guide [19]). This network has 98 fire junctions and the fire analysis results of the previous solutions are shown in Table (13).

Table 13.

Number of failed junctions in the solutions.

\begin{tabular}{|c|c|}
\hline Solution & Number of failed junction \\
\hline S1 & $19(19.4 \%)$ \\
\hline S2 & $0(0 \%)$ \\
\hline S3 & $1(1 \%)$ \\
\hline S4 & $98(100 \%)$ \\
\hline
\end{tabular}

\subsubsection{Network performance during the abnormal operation conditions}

The water pipe network may face abnormal conditions during its service time. So the network design should take these conditions into consideration to decrease its expensive side effects. The abnormal conditions are closing any pipe, leakage, closing pump suddenly and the performance of the solution after life time. 


\subsubsection{Closing any pipe}

Criticality and Segmentation analysis, which is a tool in WaterGEMS, is used to explore the side effects on the network performance (demand connectivity and the pressure at each node) by closing each pipe alone. Its results are obvious in Table (14).

Table 14.

Results of criticality and segmentation analysis for the four solutions.

\begin{tabular}{|c|c|c|c|}
\hline Solution & $\begin{array}{c}\text { Number of the closed } \\
\text { pipes that affect on } \\
\text { demand or pressure }\end{array}$ & $\begin{array}{c}\text { Number of the closed } \\
\text { pipes that affect on } \\
\text { pressure only }\end{array}$ & $\begin{array}{c}\text { The sum of the system demand } \\
\text { shortfall percentages due to } \\
\text { pipes closing }\end{array}$ \\
\hline S1 & $201(91 \%)$ & $4(1.8 \%)$ & $303.6 \%$ \\
\hline S2 & $130(58.8 \%)$ & $5(2.3 \%)$ & $131.3 \%$ \\
\hline S3 & $142(64.3 \%)$ & $2(0.9 \%)$ & $112.2 \%$ \\
\hline S4 & $277(93.9 \%)$ & $21(7.1 \%)$ & $87.4 \%$ \\
\hline
\end{tabular}

\subsubsection{Leakage}

It is assumed that every solution has two leakage points, one of them exists at the maximum pressure node and the other at the minimum pressure node. The leakage is treated here as an orifice with one inch diameter, drains water to the atmosphere. Every solution is evaluated according to the number of nodes that have pressures less than $30 \mathrm{~m}$ of water (demand shortfall) or negative pressure (constituent intrusion). The results are shown in Table (15).

\section{Table 15.}

The effect of leakage on the junctions pressure for the four solutions.

\begin{tabular}{|c|c|c|}
\hline $\begin{array}{c}\text { Solu } \\
\text { tion }\end{array}$ & $\begin{array}{c}\text { Number of nodes } \\
\text { have negative } \\
\text { pressure }\end{array}$ & $\begin{array}{c}\text { Number of nodes } \\
\text { have } \\
\mathrm{P}<30 \mathrm{~m} \text { of water }\end{array}$ \\
\hline S1 & 0 & $2(0.9 \%)$ \\
\hline S2 & 0 & 0 \\
\hline S3 & 0 & 0 \\
\hline S4 & 0 & $16(7.2 \%)$ \\
\hline
\end{tabular}

\subsubsection{Closing pump suddenly}

Any change in flow or pressure, at any point in the system, can trigger hydraulic transients. If the change is gradual, the resulting transient pressures may not be severe. However, if the change of flow is rapid or sudden, the resulting transient pressure can cause surges or water hammer. There are many possible causes for rapid or sudden changes in a pipe system, including power failures, pipe breaks, or a rapid valve opening or closure. These can result from natural causes, equipment malfunction, or even operator error. The impact of a sudden power failure is simulated here (Bentley HAMMER User's Guide [2]). It is assumed that there isn't any protection from water hammer. The purpose of this type of transient analysis is to ensure the system and its components can withstand the resulting transient pressures and to identify any negative pressure for avoiding dangerous consistent intrusion. This analysis is conducted by using Bentley HAMMER. The results of this analysis are tabulated in Table (16). 
Nashat A. Ali, et al., Evaluation of rehabilitation solutions for performance of water pipes ...

Table 16.

The number of nodes that have damaged transient pressure and negative pressure.

\begin{tabular}{|c|c|c|}
\hline Solution & $\begin{array}{c}\text { Number of nodes that have } \\
\text { transient pressure }>16 \text { bars }\end{array}$ & $\begin{array}{c}\text { Number of nodes that have negative } \\
\text { transient pressure }\end{array}$ \\
\hline S1 & 0 & $108(48.9 \%)$ \\
\hline S2 & 0 & $94(42.5 \%)$ \\
\hline S3 & 0 & $91(41.2 \%)$ \\
\hline S4 & 0 & $93(42.1 \%)$ \\
\hline
\end{tabular}

\subsubsection{After life time}

Due to budget limitation, the water utilities may not be able to carry out its future rehabilitation plans. So, the solutions performance (pressure and velocity only) after their target year by additional ten years are examined. It is assumed that the population is constant after ten years because the city will be already at the saturation level but, the Hazen-William coefficient of the pipes is assumed to deteriorate by 10 . The results are summarized in Table (17).

\section{Table 17.}

The effect of ten years age on the performance of the solutions.

\begin{tabular}{|c|c|c|}
\hline Solution & Number of nodes have $\mathrm{P}<30 \mathrm{~m}$ of water & Number of pipes have velocity $>2 \mathrm{~m} / \mathrm{sec}$ \\
\hline S1 & $41(18.6 \%)$ & $67(27.6 \%)$ \\
\hline S2 & $0(0 \%)$ & $10(4.1 \%)$ \\
\hline S3 & $0(0 \%)$ & $5(2.1 \%)$ \\
\hline S4 & $94(42.5 \%)$ & $48(15.1 \%)$ \\
\hline
\end{tabular}

\subsubsection{Water quality}

The quality of the delivered water is an important evaluation factor. The water quality evaluated according to two factors: water age and chlorine distribution. These factors are simulated by water quality analysis in WaterGEMS.

\subsubsection{Water age}

Water age analysis determines how long the water has been in the system and is more of a general water quality indicator than a measurement of any specific constituent (WaterGEMS V8i User's Guide [19]). The results are shown in Table (18).

\section{Table 18.}

The sum of the daily water age for all nodes for the four solutions.

\begin{tabular}{|c|c|}
\hline Solution & Sum of water age for all nodes during the day (hours) \\
\hline S1 & 12690.5 \\
\hline S2 & 13525.4 \\
\hline S3 & 11993.18 \\
\hline S4 & 13591.25 \\
\hline
\end{tabular}

\subsubsection{Chlorine distribution}

Chlorine analysis describes the growth or decay through the use of a bulk reaction coefficient and a wall reaction coefficient. A chlorine analysis determines the concentration of chlorine at all nodes and links in the system. It can be used to determine chlorine residuals throughout the system under present chlorination schedules, or can be used to determine probable behavior of the system under proposed chlorination schedules (WaterGEMS V8i User's Guide [19]). There is only one chlorine source in the network which is the source 
reservoir and the chlorine dose is $2 \mathrm{mg} / \mathrm{L}$. According to the World Health Organization (WHO) and Egyptian code, the concentration of chlorine in a distribution network should be less than $0.2 \mathrm{mg} / \mathrm{L}$. The results of the solutions are listed in Table (19).

\section{Table 19.}

The number of nodes which have unsafe chlorine concentration in the solutions.

\begin{tabular}{|c|c|}
\hline Solution & Number of nodes which have chlorine concentration less than $0.2 \mathrm{mg} / \mathrm{L}$ during the day \\
\hline S1 & 0 \\
\hline S2 & 0 \\
\hline S3 & 0 \\
\hline S4 & 0 \\
\hline
\end{tabular}

\subsection{Selection of the optimum solution}

From the previous results, it is obvious that there isn't any solution dominates on the others in the all mentioned factors. But, solution 3 dominates on the others in efficiency, network performance during abnormal conditions and water quality. In addition, it isn't more expensive than the others. So, solution 3 is the optimum solution. But unfortunately, solution 3 is impractical because it has a $100 \%$ of replacement percentage as mentioned before. As a result of that, it is considered that the optimum solution is the closest one to solution 3 in cost, efficiency, network performance at abnormal conditions and water quality. From Tables (10-19), one can see that the solution 2 is the optimum solution.

\subsection{Evaluation of the original network performance after applying the optimum solution}

As a matter of fact, the original network is the real image of the network that really exists in the field. So, we have to ensure that solution 2 does its duties well when loading it into the original network as shown in Fig.(5). It is assumed that the sub-pipes have $\mathrm{C}=$ 110. The results of this process are shown in Table (20).

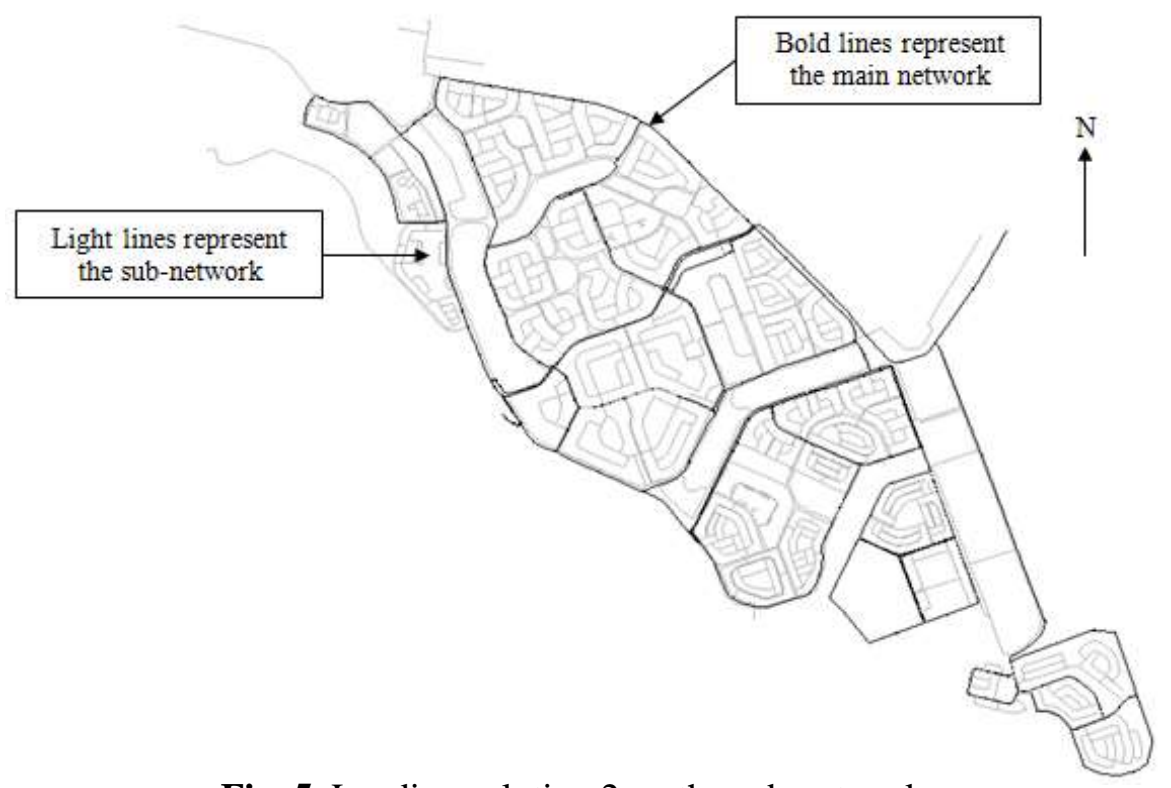

Fig. 5. Loading solution 2 on the sub-network. 
Nashat A. Ali, et al., Evaluation of rehabilitation solutions for performance of water pipes ...

\section{Table 20.}

The differences in the performance between the simplified and the original networks are within solution 2 .

\begin{tabular}{|c|c|c|c|c|}
\hline \multicolumn{2}{|c|}{ Factor } & The simplified network & The original network & Notes on the original network \\
\hline \multicolumn{2}{|c|}{$\begin{array}{l}\text { Number of nodes have } \mathrm{P}<30 \mathrm{~m} \text { of } \\
\text { water }\end{array}$} & $0(0 \%)$ & $3(0.32 \%)$ & $\begin{array}{l}\text { The least pressure of them is } 29 \\
\text { m of water. }\end{array}$ \\
\hline \multicolumn{2}{|c|}{ Number of pipes have $V>2 \mathrm{~m} / \mathrm{sec}$} & $0(0 \%)$ & $30(2.2 \%)$ & $\begin{array}{l}6.7 \% \text { of them have } V=(3-4 \mathrm{~m} / \mathrm{s}) \\
\text { and the rest have } V=(2-3 \mathrm{~m} / \mathrm{s}) \text {. }\end{array}$ \\
\hline \multicolumn{2}{|c|}{ Number of failed fire junctions } & $0(0 \%)$ & $1(1 \%)$ & $\begin{array}{l}\text { Its pressure constraint is } \mathrm{P}>27 \\
\mathrm{~m} \text { of water. }\end{array}$ \\
\hline \multicolumn{2}{|c|}{ Daily energy usage (KWh) } & $23,716.1$ & 23,0395 & \\
\hline \multicolumn{2}{|c|}{$\begin{array}{l}\text { Sum of the system demand shortfall } \\
\text { percentage due to pipes closing }\end{array}$} & $131.3 \%$ & $86.6 \%$ & \\
\hline \multirow[t]{2}{*}{ Leakage } & $\mathrm{P}<30 \mathrm{~m}$ of watez & $0(096)$ & $9(0.9596)$ & $\begin{array}{l}\text { The least pressure of them is } 28 \\
\mathrm{~m} \text { of water. }\end{array}$ \\
\hline & $\mathrm{P}<0 \mathrm{~m}$ of water & $0(0 \%)$ & $0(0 \%)$ & \\
\hline \multirow{2}{*}{$\begin{array}{l}\text { Closing pump } \\
\text { suddenly }\end{array}$} & $\mathrm{P}>16$ bars & $0(0 \%)$ & $1(0.11 \%)$ & \multirow{2}{*}{$\begin{array}{l}\text { The original network has } 943 \\
\text { nodes unlike the main which has } \\
221 \text { only. }\end{array}$} \\
\hline & $\mathrm{P}<0$ bars & $94(42.5 \%)$ & $399(42.3 \%)$ & \\
\hline \multirow[t]{2}{*}{ After life time } & $\mathrm{P}<30 \mathrm{~m}$ of water & $0(0 \%)$ & $28(29740)$ & $\begin{array}{l}32 \% \text { have } \mathrm{P}=(20-24 \mathrm{~m} \text { of water }) \\
\text { and } 53.6 \% \text { have } \mathrm{P}=(24-27 \mathrm{~m} \text { of } \\
\text { water). }\end{array}$ \\
\hline & $V>2 \mathrm{~m} / \mathrm{sec}$ & $10(4.1 \%)$ & $30(2.23 \%)$ & $\begin{array}{l}6.7^{\circ} \text { have } V=(3-4 \mathrm{~m} / \mathrm{s}) \text { and the } \\
\text { rest have } V=(2-3 \mathrm{~m} / \mathrm{s}) \text {. }\end{array}$ \\
\hline \multicolumn{2}{|c|}{$\begin{array}{l}\text { Number of nodes have Chiorine } \\
\text { concentration }<0.2 \mathrm{mg} L\end{array}$} & $0(0 \%)$ & $1(0.11 \%)$ & \\
\hline \multicolumn{2}{|l|}{ Water age (hours) } & 13525,4 & 14692.1 & \\
\hline
\end{tabular}

It is shown from Table (20), that the difference in performance between the simplified and the original networks when applying the solution 2 is very small. In some cases, the original network gives better results than the simplified one in some factors like daily energy usage and the effect of closing pipes. This case guarantees a safe and a reliable design. But, the worse is that the simplified one gives better results than the original because it seems that the design is safe but actually it is not. In spite of that, we can see that the difference between them isn't effective.

\section{Conclusions}

From the previous analysis, it is concluded that:

1. The water utility must monitor and calibrate the network to know the actual roughness size and the structural condition of pipes.

2. Eliminating the sub-pipes to simplify large networks can be acceptable if its intakes are remained on the main pipes.

3. Efficient simplification of a large network can facilitate searching for optimal solutions for the network problems.

4. There aren't any of the suggested solutions that dominate on the others in all evaluation factors.

5. The cost of construction shouldn't guide to the optimum solution alone. But, all factors that contribute in cost must be taken into consideration.

6. The demand uncertainty is a very important factor in generating the rehabilitation solutions.

7. Deterioration of the hydraulic capacity (increasing of roughness size in pipes) and physical condition of the pipes (pipes break) must be taken into consideration to generate a safe and a reliable solution. 


\section{REFERENCES}

[1] Aghmiuni, S. S., Haddad, O. B., Omid, M. H. and Marino, M. A., "Effects of Pipe Roughness Uncertainty on Water Distribution Network Performance During its Operational Period", Water Resources Management, Vol. 27, Issue 5, pp. 1581-1599, (2013).

[2] Bentley HAMMER User's Guide: Water Distribution Modeling Software (transient flow). Series 4.

[3] Cheung, P. B., Reis, L. R., Formiga, K. M., Chaudhry, F. H. and Ticona, W. C., "Multiobjective Evolutionary Algorithms Applied to the Rehabilitation of a Water Distribution System : A Comparative Study", 2nd Int. Conf., EMO 2003, Faro, Portugal, Apr. 8-11, pp. 662-676, (2003).

[4] Cisty, M., "Hybrid Genetic Algorithm and Linear Programming Method for Least-Cost Design of Water Distribution Systems", Water Resources Management, Vol. 24, Issue 1, pp. 1-24, (2009).

[5] Fontana, M. E. and Morais, D. C., "Using Promethee V to Select Alternatives so as to Rehabilitate Water Supply Network with Detected Leaks", Water Resources Management, Vol. 27, Issue 11, pp. 4021-4037, (2013).

[6] Giacomello, C., Kapelan, Z., Nicolini, M., "Fast Hybrid Optimization Method for Effective Pump Scheduling”, Jour. of Water Resources Planning and Management, Vol. 139, No. 2, pp. 175-183, (2013).

[7] Jin, X., Zhang, J., Gao, J. L. and Wu, W. Y., "Multi-objective Optimization of Water Supply Network Rehabilitation with Non-dominated Sorting Genetic Algorithm-ll", Journal of Zhejiang University SCIENCE A, pp. 391-400, (2008).

[8] Kim, J. H., Baek, C. W., Jo, D. J., Kim, E. S., and Park, M. J., "Optimal Planning Model for Rehabilitation of Water Networks", Water Science and Technology: Water Supply, Vol. 4, No. 3 pp. 133-147, (2004).

[9] Kleiner, Y., "Water Distribution Network: Selection and Scheduling of Pipe Rehabilitation Alternatives", Thesis submitted in conformity with the requirements for the degree of Doctor of Philosophy in civil Eng., Toronto university, (1997).

[10] Marzouk, M., Abdel Hamid, S., El-Said, M., "A Methodology for Prioritizing Water Mains Rehabilitation in Egypt”, HBRC jour., (2014).

[11]Nazif, S., Karamouz, M., Yousefi, M. and Zahmatkesh, Z., "Increasing Water Security: An Algorithm to Improve Water Distribution Performance", Water Resources Management, Vol. 27, Issue 8, pp. 2903-2921, (2013).

[12]Park, S., "Estimating the Timing of the Economical Replacement of Water Mains Based on the Predicted Pipe Break Times Using the Proportional Hazards Models", Water Resources Management, Vol. 25, Issue 10, pp. 2509-2524, (2011).

[13] Popawala, R. and Shah, N. C., "Condition Assessment Model for Underground Water Mains Performance", Jour. of The Institution of Engineers (India): Series A, Vol. 95, Issue 4, pp. 195-201, (2014).

[14]Renaud, E., Le Gat, Y. and Poulton, M., "Using a Break Prediction Model for Drinking Water Networks Asset Management: from Research to Practice", Water Science \& Technology: Water Supply, Vol. 12, No. 5, PP. 674-682, (2012).

[15]Savic, D. A., "Coping With Risk and Uncertainty in Urban Water Infrastructure Rehabilitation Planning", 12th International Water Technology Conference, IWTC12 2008 Alexandria, Egypt, (2005).

[16] Shibu, A. and Reddy, M. J., “Optimal Design of Water Distribution Networks Considering Fuzzy Randomness of Demands Using Cross Entropy Optimization", Water Resources Management, Vol. 28, Issue 12, pp. 4075-4094, (2014).

[17] Siew, C., Tanyimboh, T. T. and Seyoum, A. G., "Assessment of Penalty-Free MultiObjective Evolutionary Optimization Approach for the Design and Rehabilitation of Water Distribution Systems", Water Resources Management, Vol. 28, Issue 2, pp. 373-389, (2014).

[18] Tabesh, M. and Saber, H., "A Prioritization Model for Rehabilitation of Water Distribution Networks Using GIS”, Water Resources Management, Vol. 26, Issue 1, pp. 225-241, (2012).

[19] WaterCAD User's Guide: Water Distribution Modeling Software. Series 4. 
Nashat A. Ali, et al., Evaluation of rehabilitation solutions for performance of water pipes ...

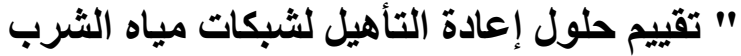

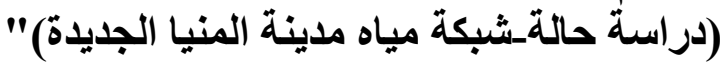

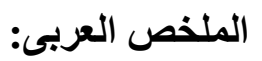

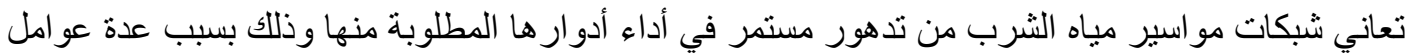

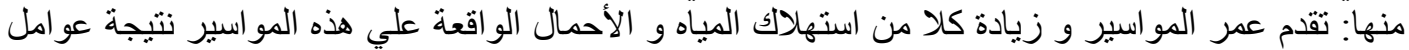

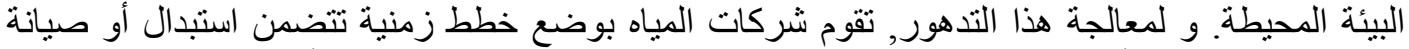

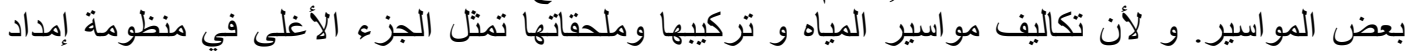

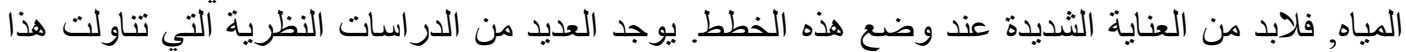

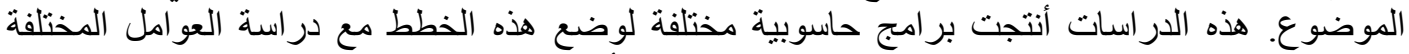

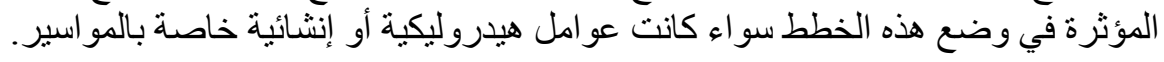

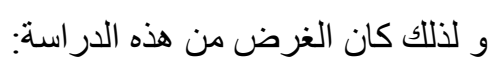

1- 1- وضع حلول لثبكة المنيا الجديدة كحالة در استة لفترة زمنية محددة.

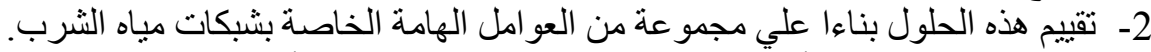

3- محاولة اختيار الحل الأفضل مع مر اعاة كافة العوامل الهامة الأخرى.

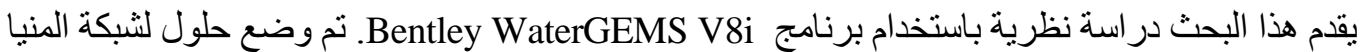

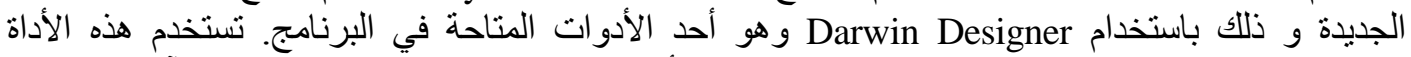
Genetic Algorithm (GA)

1- يجب أن تقوم شركة المباه المسئولة بعمل معايرة للشبكة للتعرف علي خشونة المو اسير و الحالة

الإنشائية لها.

2- إلغاء المو اسير الفرعية في الثبكات الكبيرة لتبسيطها يمكن أن يكون مقبول في حالة الإبقاء علي

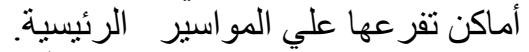

3- التبسيط الكفء للثبكات الكبيرة إلي أخري أصغر يسهل من عملية البحث عن حلول مثلى لمشاكل

هذه الثبكات.

4- لا يو جد حل من الحلول المقترحة متفوق علي الحلول الأخرى في كل عو امل المقارنة.

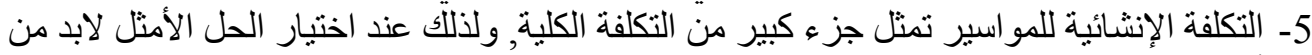

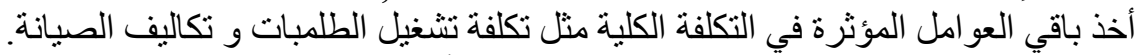

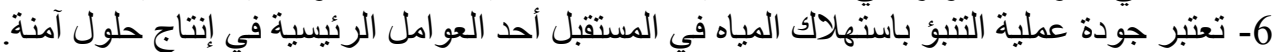

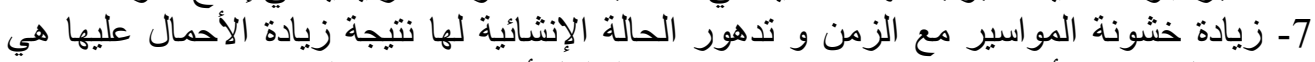

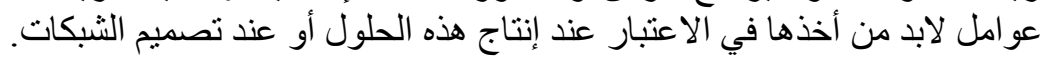

